\section{Tunable reagents for multi-functional bioconjugation: reversible or permanent chemical modification of proteins and peptides by control of maleimide hydrolysis $\dagger$}

\author{
Chris P. Ryan, ${ }^{a}$ Mark E. B. Smith, ${ }^{a}$ Felix F. Schumacher, ${ }^{a}$ Dina Grohmann, ${ }^{b}$ \\ Danai Papaioannou, ${ }^{c}$ Gabriel Waksman, ${ }^{c}$ Finn Werner, ${ }^{b}$ James R. Baker* ${ }^{* a}$ and \\ Stephen Caddick*a
}

Received 24th February 2011, Accepted 22nd March 2011

DOI: $10.1039 / \mathrm{c} 1 \mathrm{cc} 11114 \mathrm{k}$

Controlling maleimide hydrolysis allows the modular construction of bromomaleimide-mediated bioconjugates which are either stable or cleavable in an aqueous, thiol-mediated reducing environment. The application of this methodology to reversible protein biotinylation, the irreversible labeling of peptide disulfide bonds and the assembly of stable, fluorescein-labelled glycoprotein mimics is described.

The advent of chemical biology has demonstrated the power of integrating synthetic chemistry methods with molecular biology to derive functionally interesting proteins either as probes or therapeutics. Chemical modification of proteins has allowed the synthesis of a variety of probes via introduction of synthetic post-translational modifications ${ }^{1-3}$ and a variety of fluorescent, ${ }^{4-6}$ radiolabelled $^{7}$ and affinity tags. ${ }^{8-10}$ The selective chemical modification of the sulfhydryl group of cysteine has proved a facile method to achieve protein modification. This is due to the rare occurrence of free cysteine in protein sequences, the fact that it is the most nucleophilic of all amino acid side chain residues and that in principle modern molecular biology methods allow the introduction of a free cysteine anywhere in a protein. ${ }^{11,12}$

We recently described an approach to reversible cysteine bioconjugation using bromomaleimides, that allows the modular construction of complex bioconjugates in very high yields with no requirement for prior activation of reactants. ${ }^{13}$ However, although reversible labeling of peptides and proteins is of considerable value, there are many circumstances under which a permanent, irreversible modification is required. We now wish to report the development of maleimides that maintain three points of chemical attachment but whose stability can be

${ }^{a}$ Department of Chemistry, University College London,

20 Gordon Street, London WC1H OAJ, UK.

E-mail: s.caddick@ucl.ac.uk; Tel: +44(0)2031085071

${ }^{b}$ Research Department of Structural and Molecular Biology,

University College London, Gower Street, London WC1E 6BT, UK

${ }^{c}$ Institute of Structural and Molecular Biology at UCL/Birkbeck,

Malet Street, London WC1E $7 H X, U K$

$\dagger$ Electronic supplementary information (ESI) available: Full experimental details and characterisation. See DOI: $10.1039 / \mathrm{clcc} 11114 \mathrm{k}$ controlled by a simple hydrolysis protocol so that they can be either cleavable or stable in the presence of an aqueous, thiol-mediated reducing environment. Such control of stability allows the synthesis of a range of complex bioconjugates with significantly different potential. In principle, stable conjugation allows the construction of non-cleavable PTM mimics suitable for evaluation as probes or therapeutics. Cleavable conjugates could be used to generate reversible affinity and fluorescent labels, or constructs cleavable under cytoplasmic conditions with potential as prodrugs.

We noted that though maleimides react in a facile manner with thiol nucleophiles, maleamic acids do not (see ESI $\dagger$ ). We therefore considered that it should be possible to convert a reversible maleimide-based bioconjugation to an irreversible bioconjugation by careful choice of reagent and through careful hydrolysis of the original bioconjugate. The realisation of this concept was demonstrated by use of $\mathrm{N}$-phenyl-bromomaleimides $\mathbf{2}$ and $\mathbf{5}$. The susceptibility of $N$-arylmaleimides to hydrolysis has been previously reported in the literature. ${ }^{14}$

We exemplified our approach using a single point mutant (L111C) of the SH2 domain of the Grb2 adapter protein $\mathbf{1}^{13 a}$ Thus treatment of protein $\mathbf{1}$ with a stoichiometric equivalent of $\mathrm{N}$-phenylbromomaleimide 2 at $\mathrm{pH} 8,0{ }^{\circ} \mathrm{C}$ for $1 \mathrm{~h}$ yielded 3 . Conjugate 3 was stable at $0{ }^{\circ} \mathrm{C}$ but on heating to $37^{\circ} \mathrm{C}$ for $4 \mathrm{~h}$, quantitative hydrolysis of the maleimide was observed to give 4, presumably as a mixture of regioisomers, which was completely stable to 2-mercaptoethanol (BME) and glutathione (GSH) $\left(0{ }^{\circ} \mathrm{C}, 20{ }^{\circ} \mathrm{C}, 37^{\circ} \mathrm{C}\right)$ (Scheme 1$)$.

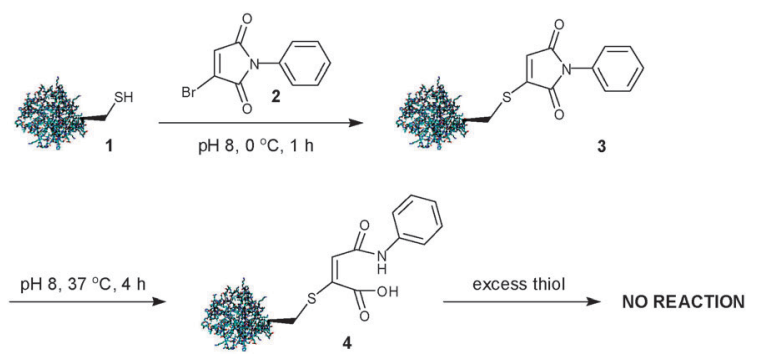

Scheme 1 From reversible to irreversible protein modification with $N$-phenylbromomaleimide. 


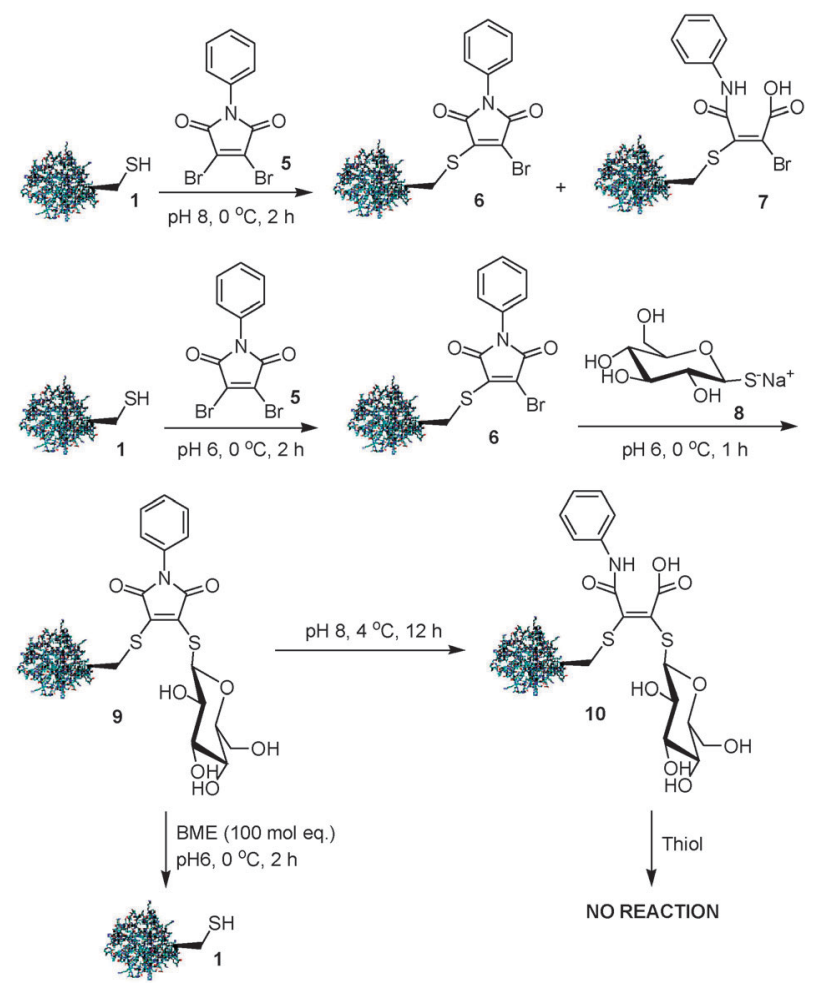

Scheme 2 Irreversible protein bioconjugation using $N$-phenyl-dibromomaleimide.

Hydrolysis of conjugates of protein 1 with $N$-phenyldibromomaleimide $\mathbf{5}$ was even more facile. Treatment of protein $\mathbf{1}$ with one equivalent of 5 at $\mathrm{pH} 8$ gave a $7: 3$ mixture of maleimide 6 and hydrolysed product 7 even at $0{ }^{\circ} \mathrm{C}$. However, performing the same procedure at $\mathrm{pH} 6$ allowed clean conversion of protein $\mathbf{1}$ to $\mathbf{6}$, and then treatment of $\mathbf{6}$ with one equivalent of thioglucose, sodium salt $\mathbf{8}$ furnished bioconjugate 9 . Bioconjugate 9 was shown to be hydrolytically stable at $\mathrm{pH} 6,0{ }^{\circ} \mathrm{C}$ for $>4 \mathrm{~h}$. Treatment of 9 with excess BME at $0{ }^{\circ} \mathrm{C}$ gave complete cleavage to protein 1. Exchanging the buffer environment of a solution of bioconjugate 9 from $\mathrm{pH} 6$ to 8 yielded bioconjugate $\mathbf{1 0}$ which was stable to $\mathrm{BME}$ and $\mathrm{GSH}\left(0{ }^{\circ} \mathrm{C}, 20^{\circ} \mathrm{C}, 37^{\circ} \mathrm{C}\right)$, highlighting that maleimide hydrolysis could be utilized to stabilize an assembled bioconjugate to thiol-mediated cleavage (Scheme 2).

With methods in hand to generate both cleavable and stable maleimide-bridged bioconjugates we sought to demonstrate the strength and versatility of this methodology with some specific examples.

Use of the biotin-avidin interaction, to facilitate biotinlabelled protein enrichment or immobilisation, is a well established technique. ${ }^{15}$ The method is, however, limited by the fact that breaking of this interaction, to ultimately retrieve the protein sample, requires very harsh, denaturing conditions which are not experimentally useful, e.g. boiling buffer containing sodium dodecyl sulfate (SDS) or $8 \mathrm{M}$ guanidine ( $\mathrm{pH}$ 1.5). Two strategies have been developed to address this problem. The first approach requires design of analogues of biotin which bind with lower affinity to avidin. ${ }^{16}$ Though very useful, this approach is hampered as increased ease of elution comes at the price of weaker initial binding. A second

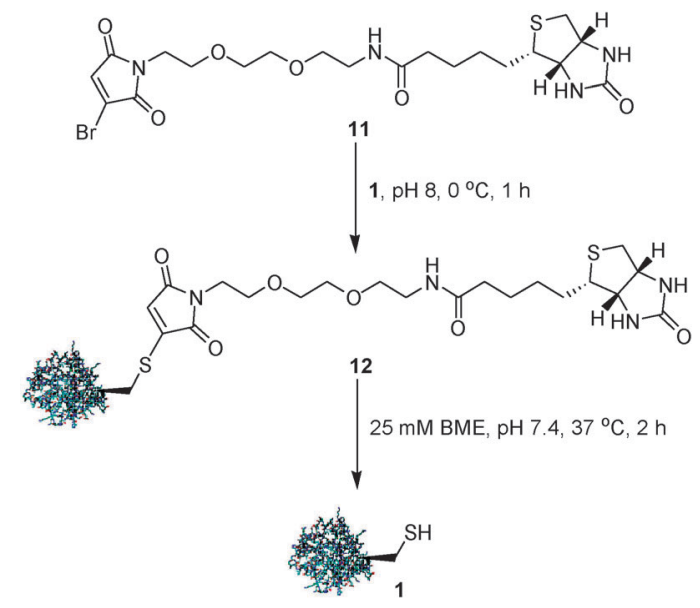

Scheme 3 Cleavable biotinylation of protein $\mathbf{1}$ with affinity tag $\mathbf{1 1}$.

approach is to design affinity probes which maintain the native biotin-avidin interaction but which incorporate a cleavable linker. ${ }^{8,9}$ Given the robust hydrolytic stability of $N$-methylbromomaleimide-modified $\mathbf{1}$ (stable for $4 \mathrm{~h}, \mathrm{pH} 8,37^{\circ} \mathrm{C}$, see ESI $\dagger$ ), we were encouraged to design and synthesise cleavable affinity tag 11 (Fig. S1, see ESI $\dagger$ ). We envisaged that this tag would allow facile pull-down of proteins onto an avidinmodified surface whilst supporting mild cleavage conditions in $\mathrm{mM}$ concentrations of BME. BME is widely used in molecular biology and is known to be compatible with proteins. A further potential advantage of tag $\mathbf{1 1}$ is that native protein would be released upon cleavage.

To demonstrate the utility of $\mathbf{1 1}$, we attempted the derivatisation, pull-down and release of protein 1. Treatment of $\mathbf{1}$ with a stoichiometric equivalent of $\mathbf{1 1}$ at $\mathrm{pH} 8,0{ }^{\circ} \mathrm{C}$ gave quantitative conversion to the desired biotinylated conjugate 12 after $1 \mathrm{~h}$. Conjugate $\mathbf{1 2}$ was demonstrably stable in the absence of thiol $\left(37^{\circ} \mathrm{C}, \mathrm{pH} 8,1 \mathrm{~h}\right)$. The protein solution was then applied to neutravidin-coated agarose beads to facilitate protein pull-down. Release of $\mathbf{1}$ from the beads was successfully achieved on suspension in PBS buffer containing $25 \mathrm{mM} \mathrm{BME}$ for $2 \mathrm{~h}$ at $37^{\circ} \mathrm{C}$ (Scheme 3).

We believe that BME initially reacts with $\mathbf{1 2}$ to generate the saturated bisthio adduct. ${ }^{13 a}$ At elevated temperatures, this adduct can undergo a reversible retro-Michael reaction which allows liberation of the protein in an excess of the thiol. $77 \%$ of immobilized protein was recovered following this pull-down/ release protocol (see ESI $\dagger$ for gels and detailed experimental).

Fluorescent labeling of proteins is a powerful technique for studying localization, protein dynamics and protein-protein interactions. ${ }^{17}$ Within the field of medical imaging, optical imaging is becoming more widely used as a technique as it has a sensitivity of the same order as radionuclide imaging, with far greater spatial and temporal resolution, and no requirement for radioactive materials. We have previously reported that dibromomaleimide reagents can be used successfully to reversibly modify the disulfide bond of peptide hormone somatostatin. ${ }^{13 a}$ To exemplify this discovery, we demonstrated the reversible insertion of a fluorescent probe into the disulfide bond. We now wish to demonstrate how when using an $\mathrm{N}$-arylmaleimide derived fluorophore this process can be made irreversible ensuring the potential for continued attachment of the 


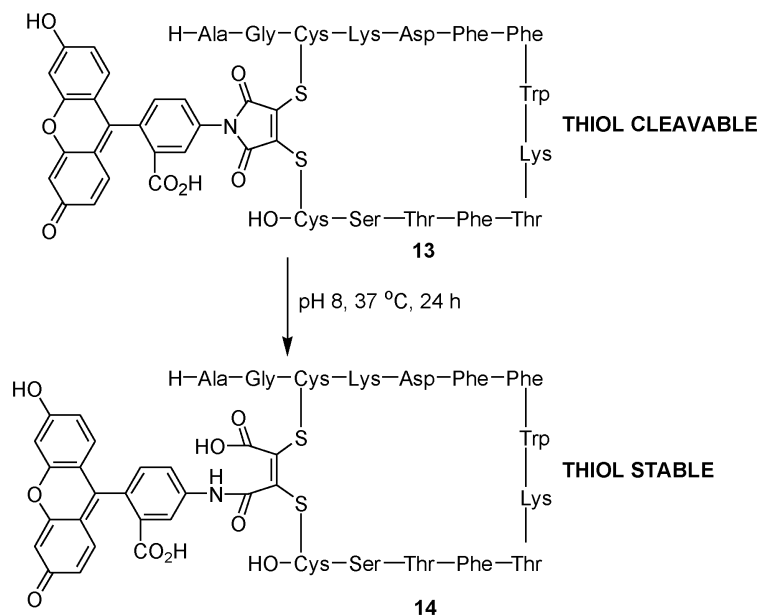

Scheme 4 Reversible and irreversible fluorescent labelling of somatostatin.

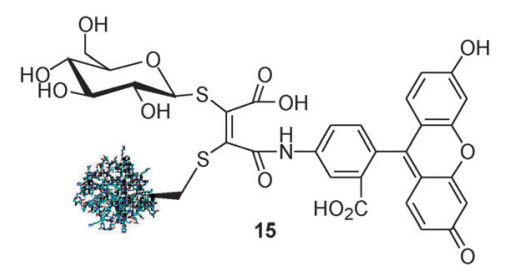

Scheme 5 Non-cleavable, fluorescent glycoprotein mimic.

fluorophore in a biological environment. Somatostatin was modified with $N$-fluoresceindibromomaleimide $(\mathrm{pH}$ 6.2) to yield cleavable conjugate $\mathbf{1 3}$ as previously described. ${ }^{13 a}$ Heating the solution of $\mathbf{1 3}(\mathrm{pH} 8)$ to $37{ }^{\circ} \mathrm{C}$ for $24 \mathrm{~h}$ facilitated complete maleimide hydrolysis yielding non-cleavable conjugate 14 (Scheme 4).

A similar strategy can also be employed to generate non-cleavable, fluorescent bioconjugates via the modification of a single cysteine residue. Applying the bioconjugate assembly strategy outlined in Scheme 2 to protein 1, but using $N$-fluoresceindibromomaleimide in place of $\mathbf{5}$, gave access to non-cleavable, fluorescently-labelled glycoprotein mimic $\mathbf{1 5}$ (Scheme 5).

In conclusion, we have demonstrated the use of bromomaleimides for the generation of complex bioconjugates, maintaining three points of attachment, which are either cleavable or non-cleavable in the presence of an excess of thiol such as BME or GSH. The switch from reversible modification to an irreversible linkage was achieved by controlled maleimide hydrolysis post-conjugate assembly. $\mathrm{N}$-alkylated mono- or bisthio-maleimides appear quite stable to hydrolysis, even at $\mathrm{pH} 8$ and physiological temperature, yielding conjugates which are cleavable in an excess of thiol. $\mathrm{N}$-arylated mono- or bisthio-maleimides can be assembled in a facile manner at $\mathrm{pH} 6$ but hydrolyse rapidly at $\mathrm{pH} 8$ yielding conjugates which are non-cleavable. We have demonstrated that thiol-mediated cleavage can be applied to the design and application of a novel affinity tag which allows the successful pull-down of a cysteine containing protein onto neutravidin beads. Cleavage, under mild conditions, releases the native protein in good yield. We have also demonstrated the synthesis of both fluorescently-labelled and unlabelled, thiol-stable glycoprotein mimics and thiol-stable fluorescent labeling of a disulfide bond. We envisage numerous potential applications for these technologies including PTM of proteins; affinity tagging and protein labelling; PEGylation; prodrugs designed to cleave in cells. Further applications and developments using this versatile methodology will be reported in due course. The authors are grateful to RCUK, EPSRC, BBSRC, the Wellcome Trust and UCLB for support of our programme.

\section{Notes and references}

1 S. I. Van Kasteren, H. B. Kramer, H. H. Jensen, S. J. Campbell, J. Kirkpatrick, N. J. Oldham, D. C. Anthony and B. G. Davis, Nature, 2007, 446, 1105.

2 B. G. Davis, Science, 2004, 303, 480.

3 K. L. Kiick, E. Saxon, D. A. Tirrell and C. R. Bertozzi, Proc. Natl. Acad. Sci. U. S. A., 2002, 99, 19.

4 K. Kikuchi, Chem. Soc. Rev., 2010, 39, 2048.

5 K. Lymperopoulos, A. Kiel, A. Seefeld, K. Stohr and D.-K. Herten, ChemPhysChem, 2010, 11, 43.

6 N. Johnsson and K. Johnsson, ACS Chem. Biol., 2007, 2, 31.

7 V. Tolmachev and S. Stone-Elander, Biochim. Biophys. Acta, Gen. Subj., 2010, 1800, 487.

8 A. Dirksen, S. Yegneswaren and P. E. Dawson, Angew. Chem., Int. Ed., 2010, 49, 2023.

9 A. E. Speers and B. F. Cravatt, J. Am. Chem. Soc., 2005, 127, 10018.

10 S. H. L. Verhelst, M. Fonovic and M. Bogyo, Angew. Chem., Int. Ed., 2007, 46, 1284.

11 R. L. Lundblad, Chemical Reagents for Protein Modification, CRC Press, Boca Raton, FL, 3rd edn., 2005.

12 J. M. Chalker, G. J. L. Bernardes, Y. A. Lin and B. G. Davis, Chem.-Asian J., 2009, 4, 630.

13 (a) M. E. B. Smith, F. F. Schumacher, C. P. Ryan, L. M. Tedaldi, D. Papaioannou, G. Waksman, S. Caddick and J. R. Baker, J. Am. Chem. Soc., 2010, 132, 1960; (b) L. M. Tedaldi, M. E. B. Smith, R. Nathani and J. R. Baker, Chem. Commun., 2009, 6583; (c) F. F. Schumacher, M. Nobles, C. P. Ryan, M. E. B. Smith, A. Tinker, S. Caddick and J. R. Baker, Bioconjugate Chem., 2011, 22, 132; (d) J. R. Baker, S. Caddick and M. E. B. Smith, Patent applications 0913965.0 (reversible covalent linkage of functional moieties), 0913967.6 (functionalization of solid substrates), 0914321.5 (thiol protecting group), 2009.

14 M. Machida, M. I. Machida and Y. Kanaoka, Chem. Pharm. Bull., 1977, 25, 2739.

15 N. M. Green, Methods Enzymol., 1990, 184, 51.

16 J. D. Hirsch, L. Eslamizar, B. J. Filanoski, N. Malekzadeh, R. P. Haughland, J. M. Beechem and R. P. Haughland, Anal. Biochem., 2002, 308, 343.

17 G. T. Hermanson, Bioconjugate Techniques, Academic Press, San Diego, 1996. 